\title{
El ideal cosmopolita, el nacionalismo y el derecho a la autodeterminación de los pueblos en el sistema internacional contemporáneo
}

\author{
Luis Ochoa Bilbao* \\ Rogelio Regalado Mujica**
}

RESUMEN

El artículo hace una revisión de la perspectiva cosmopolita que reflexiona sobre el nacionalismo y el derecho a la autodeterminación de los pueblos en el siglo Xxi. El argumento central propone que los reclamos soberanistas no desaparecerán, pero la comunidad internacional busca generar condiciones para que este fenómeno se realice mediante mecanismos democráticos y defendiendo los derechos humanos. Por lo tanto, si un nuevo pueblo apela a su independencia, deberá hacerlo bajo el marco del ideal humano céntrico y cosmopolita.
Palabras clave: nacionalismo, autodeterminación, cosmopolitismo, Estados nacionales, independencia.

\section{Cosmopilatism, natioalism and the rigth of self-determination in the contemporary international sistem}

\section{ABSTRACT}

The article offers a review of the cosmopolitan perspective that reflects upon nationalism and

\footnotetext{
* Licenciado en relaciones internacionales por la Universidad de las Américas Puebla, maestro en sociología por la Universidad Nacional Autónoma de México y doctor en sociología por la Benemérita Universidad Autónoma de Puebla. Director de la Facultad de Derecho y Ciencias Sociales de la Benemérita Universidad Autónoma de Puebla. Puebla, (México) [luis.ochoa@correo.buap.mx].

** Licenciado en relaciones internacionales por la Benemérita Universidad Autónoma de Puebla y maestrando en sociología por la misma universidad. Docente en las licenciaturas de Relaciones Internacionales y Ciencias Políticas en el Instituto de Ciencias Jurídicas de Puebla. Puebla, (México) [rogelio-mujica@hotmail.com].
}

Recibido: 28 de marzo de 2018 / Modificado: 25 de junio de 2018 / Aceptado: 16 de julio de 2018

Para citar este artículo:

Ochoa Bilbao, L. y Regalado Mujica, R. (2018). El ideal cosmopolita, el nacionalismo y el derecho a la autodeterminación de los pueblos en el sistema internacional contemporáneo. OASIS, 28, pp. $25-43$.

Dor: https://doi.org/10.18601/16577558.n28.03 
the right of self-determination of the peoples in the Twenty First Century. The main argument stresses that even though sovereignist claims won't disappear, the international community seeks to develop new conditions so as to frame this phenomenon within democratic mechanisms defending human rights. Therefore, if new local people appeal for their independence, they shall do it under the ideal human-centric and cosmopolitan framework.

Key words: Nationalism, self-determination of the peoples, cosmopolitanism, Nation states, Independence.

\section{INTRODUCCIÓN}

El sistema internacional contemporáneo está compuesto de 193 países reconocidos por la Organización de las Naciones Unidas. En todos los casos, hay una constante: la existencia de un Estado nacional que se asume como la legítima entidad organizadora de la vida económica, política y cultural de sus ciudadanos, que se considera garante de la seguridad de sus fronteras y la gestora de la política internacional. Por lo tanto, independientemente de las dimensiones, de la población, de la ubicación geográfica, del origen histórico y del modelo político o económico, el sistema internacional contemporáneo se compone de Estados nacionales ${ }^{1}$.

Este planteamiento resulta obvio y parecería innecesario repetirlo. Sin embargo, el sistema internacional compuesto por Estados nacionales no es estático, por el contrario, muchas colectividades humanas contemporáneas apelan al derecho a la autodeterminación de los pueblos para consolidar sus propios Estados nacionales. Se trata de un fenómeno que adquiere nuevos matices porque la comunidad internacional exige nuevos argumentos, tanto para los contenidos discursivos nacionalistas como para justificar el derecho a la autodeterminación de los pueblos. El propósito de este artículo es ilustrar y reflexionar sobre el nuevo perfil retórico que deben tener los pueblos y las comunidades subnacionales, que aspiran a convertirse en naciones y que buscan conquistar su independencia. El argumento del artículo es que, en el siglo XxI, todo movimiento de reivindicación nacionalista y soberanista intenta legitimarse dentro de los márgenes del cosmopolitismo para evitar, al menos, la oposición inmediata de la comunidad internacional. Esto no significa que el derecho a la autodeterminación se conquiste fácilmente por vías cosmopolitas, pero requiere justificarse bajo el marco humano-céntrico del liberalismo, las consultas populares o los referéndum.

El artículo está dividido en tres apartados. El primero y el segundo ilustran los planteamientos teóricos contemporáneos que enmarca la comprensión de los fenómenos del nacionalismo y el derecho a la autodeterminación de los pueblos en el siglo xxI. El tercero

\footnotetext{
1 En realidad, no es que demos por sentada la fragmentación de las relaciones internacionales y del mismo sistema internacional en Estados nacionales. Reconocemos los debates alrededor de la derivación del Estado que nos hace cuestionar el núcleo de esta afirmación (Véase Bonnet y Piva, 2017). Lo cierto es que, en términos concretos, el mundo se fragmenta en aparatos burocráticos administrativos fundamentalmente articulados en Estados nacionales, por lo que es necesario considerarlos en cualquier análisis contemporáneo.
} 
reflexiona, mediante algunos ejemplos soberanistas contemporáneos, aquellos escenarios que se alejarían del ideal cosmopolita y aquellos que lo persiguen. Finalmente, se aportan algunas conclusiones generales que sugieren la existencia de un debate vigente en el sistema internacional.

\section{NACIONALISMO, COSMOPOLITISMOY EL DERECHO A LA AUTODETERMINACIÓN DE LOS PUEBLOS EN LA TEORÍA}

La perspectiva teórica que mejor explica las transformaciones de las retóricas nacionalistas y del concepto de autodeterminación es la sociología histórica de las relaciones internacionales. La sociología histórica es una subdisciplina de la sociología. Su enfoque es de largo plazo y se aboca a estudiar las constantes y las variables de los procesos con una mirada de amplio horizonte, por lo cual solo se detiene a explicar problemas coyunturales en la medida que le permitan ilustrar los fenómenos históricos y sociales de forma macroscópica.

Para la sociología histórica, lo que denominamos relaciones internacionales es parte de un proceso global que comenzó con la conformación de los Estados modernos en Europa y su paulatina expansión mundial (Elias, 1994; Wallerstein, 1999; Giddens, 2006). Los Estados modernos representan una forma de organización del poder que aspira a la consolidación de la racionalidad institucional y, por ende, a formas políticas y sociales diferentes de las tradicionales, basadas en el carisma, el patrimonialismo, el patriarcado o la fuerza. El Estado moderno es, para la sociología histórica, un proceso y una aspiración, no exentos de con- flictos y contradicciones. Por lo tanto, el objeto de estudio de la sociología histórica es "analizar las relaciones entre el microacontecimiento y el conjunto, la estructura o el sistema" (Aron, 1966 , p. 325). Esto es, el proceso de construcción de Estados modernos al interior de las sociedades y el proceso de construcción de un sistema mundial en el que los actores privilegiados son los Estados nacionales.

Por otra parte, la teoría crítica también nos ayuda a comprender la forma en que el Estado nacional se despliega en el movimiento de la modernidad. Particularmente en Dialéctica del Iluminismo, Adorno y Horkheimer (1987) nos ayudan a comprender la forma en la que la Ilustración, en su intento de disipar las sombras del mundo del mito, vino a generar un nuevo mito racionalizado. El Estado nacional, en este sentido, vendría a ocupar el papel del hijo secularizado del Estado absolutista, que de igual manera construirá un entramado de símbolos y rituales que desplazarán aquellos formados durante el período previo a la modernidad.

Los Estados modernos no solo reflejan la institucionalización de la gestión económica o los equilibrios de poder entre los actores sometidos a la organización de la vida dentro de fronteras físicas definidas pacífica o violentamente. Los Estados modernos, como ha quedado claramente explicado por varios autores (Hobsbawm, 1990; Anderson, 1991; Touraine, 2000; Smith, 2010, 1988; Gellner, 1983), también construyeron a lo largo de su historia elementos de identidad nacional que les permitieran simple y sencillamente sobrevivir y ser viables.

El concepto de Estado nacional implica la idea de una entidad gestora y administrativa 
que regula las relaciones de poder dentro de las sociedades, construyendo procesos institucionales de recambio generacional. Esto es el Estado. A su vez, construye y disemina significados compartidos entre los miembros de dicha sociedad partiendo de la noción de identidad que apela a hechos históricos o heroicos, que resalta valores morales, culturales o religiosos compartidos y que, por definición, distingue a su colectividad de las otras. Esto es la nación (Stavenhagen, 2000, p. 373).

La sociología histórica narra ese proceso de quinientos años, pero se centra en los fenómenos europeos y en lo que se ha denominado el proceso civilizatorio. El surgimiento de los Estados nacionales en Occidente estuvo acompañado, como no podía ser de otra forma, por la tensión y la confrontación de grupos humanos que trataron de imponer una idea de nación y los otros grupos que la resistían. Fue la centralización del poder la que le otorgó cierto grado de éxito a las élites que consolidaron los Estados nacionales modernos; fue también la centralización de la gestión y la simplificación de los trámites burocráticos y administrativos, la organización de los ejércitos, la acumulación de capital y su impacto social que tarde o temprano se cristalizaría en otro concepto fundamental de la modernidad: la ciudadanía ${ }^{2}$.

El resto del mundo aprendió, asimiló y adaptó, sin tener otra opción, las formas de organización europea diseminadas por vías fundamentalmente violentas. Al final de la era del poderío colonial e imperial de Europa, los grupos humanos comenzaron a definir fronteras y a construir sus propios Estados nacionales. Esto implicó varios problemas:

1. Los nuevos Estados eran pobres, ineficientes e incapaces de administrar correctamente la riqueza, el territorio y sus poblaciones. A la vez, potencias externas y diferentes grupos en conflicto pelearon por acceder al poder estatal generando inestabilidad interna.

2. Dicha inestabilidad hizo que muchos de los Estados jóvenes se enfrentaran a sus vecinos, perdiendo territorio o se vieran expuestos a las naciones europeas o potencias nacientes como Estados Unidos en el continente americano, cayendo bajo su control a través de mecanismos diversos como las deudas, la inversión o la invasión militar.

3. Al mismo tiempo de construir un Estado eficiente, la nueva nación tenía también que construir una identidad propia y eso traería consigo la adopción de criterios y valores culturales determinados en detrimento de otros criterios y valores culturales. Esta tensión, por ejemplo, en América, reflejaría la imposición de un modelo nacional basado en la experiencia criolla citadina en contraposición a los modos de vida rurales e indígenas. En algunos casos se trataría de exterminar a las poblaciones originarias y en otros se

2 A este proceso se le puede sumar también una perspectiva disciplinaria. La comunidad imaginada en su forma de Estado nacional, la más desarrollada hasta el momento de esta forma política, desplazó las sensibilidades que se generaban al interior de las comunidades concretas. Este proceso, en su versión más vertical, necesitó del disciplinar a los cuerpos y mentes de los sujetos, generando la relación de docilidad-utilidad que Michel Foucault (2009) denomina disciplinas. 
les trataría de asimilar. El resultado final nunca sería el imaginado en sus inicios.

4. Pero el problema más profundo fue la construcción de una narrativa histórica que copiaba, sin ningún pudor, la narrativa occidental. Es decir, se dio una apropiación del discurso civilizatorio occidental en aquellos grupos dominantes que decidieron, difundieron e impusieron los matices y ejes de una identidad nacional implicando que esta sería moderna, emancipadora, libertaria y ciudadana.

Fundamentalmente, los nuevos Estados nacionales que surgirían desde las independencias latinoamericanas en el siglo XIX y hasta la última oleada independentista en África, en los años setenta del siglo xx, y en Europa oriental y el centro de Asia en los años noventa del mismo siglo, insistirían en copiar el modelo occidental. La única forma legítima de ser un Estado nacional era bajo el esquema clásico de los Estados nacionales europeos. De esta manera, el mundo sería testigo de los discursos clásicos del nacionalismo que iba de la mano con la noción de soberanía en la que el derecho a la autodeterminación debía ganarse por la vía violenta o de la confrontación. Esto se debía a que el orden internacional estaba bajo el control de unas cuantas potencias que trataban de mantener el privilegio de decidir qué naciones debían ser independientes y cuáles no. De igual forma, los Estados nacionales vecinos de cualquier otro Estado que apelara a la autodeterminación podrían tratar de impedir su surgimiento.

Pero las naciones, al interior, fueron transformando también sus propias ideas sobre la legitimidad del Estado respecto a las libertades de los ciudadanos. Si las naciones tienen el derecho a existir, los ciudadanos también con los derechos y atributos que les corresponderían por el solo hecho de su naturaleza humana. En este terreno entra en juego la idea de cosmopolitismo, cuyo contenido filosófico se sostiene en el argumento de que un mundo conformado por Estados-nacionales justos y legales, propiciarían el escenario ideal para que los ciudadanos de un país gozaran de los mismos derechos en cualquier parte del globo $y$, por ende, todo el mundo se convertiría en hogar de cualquier ciudadano (Appiah, 2007; Held, 2010). Por supuesto, el cosmopolitismo vendría a ser una transformación más, desde el punto de vista de los supuestos filosóficos occidentales, que explicaría y justificaría las modificaciones a cualquier reivindicación nacionalista y cosmopolita contemporáneas, como se verá a continuación ${ }^{3}$.

3 Hasta el momento, la idea que se había discutido con mayor énfasis desde la década de los 90, había sido la de la globalización neoliberal, cuyo modelo también sustentaba un mundo que conformaría una gran aldea. En realidad, esta narrativa de la globalización se ha encontrado con múltiples desafíos y la crisis misma de su propuesta, que se expresó no solo desde la izquierda progresista en América Latina sino también en Occidente con el redimensionamiento de la ultraderecha. Debemos de considerar como un debate aparte los puntos en los que el discurso de la globalización se enfrenta con los del cosmopolitismo; por el momento, la distinción radica en entender a la globalización neoliberal más como un proceso cuyo centro gira alrededor de la idea de la liberalización del flujo del capital y su subsecuente proyecto cultural. 
2. LAS TRANSFORMACIONES CONCEPTUALES DEL NACIONALISMO Y DEL DERECHO A LA AUTODETERMINACIÓN ${ }^{4}$

En el ámbito de las argumentaciones académicas, se parte de que los conceptos de nacionalismo y autodeterminación han sufrido considerables cambios teóricos por las razones que a continuación se detallan:

1. Desarrollos en la teoría política liberal han cuestionado el uso y la validez de invocar conceptos políticos que implican intereses irreduciblemente colectivos. Desde el común "interés público", pasando por "intereses de la comunidad" hasta el concepto que nos concierne aquí de "autodeterminación popular". Uno ya no puede fácilmente sostener, cuando hace referencia a una sociedad, que esta constituya algo más grande o mayor que la suma de sus partes. Desde una visión humano-céntrica o cosmopolita, los intereses de tales entidades deben confinarse a "los intereses de las personas y nada más" (Dahl, 1989, pp. 72-73). En la misma línea de argumentación, John Rawls propone concebir a una sociedad como un "sistema equitativo de cooperación" no como una comunidad, ni tampoco como una asociación. Como sistema equitativo de cooperación la sociedad no tiene 'ni fines ni propósitos últimos' los individuos ingresan a esa sociedad por nacimiento y salen al morir, no tienen identidad previa cuando ingresan y, consecuentemente, no heredan obligaciones a sus descendientes (Rawls, 1993, pp. 40-43). Críticos de esta perspectiva destacan que esto reduce a la sociedad a ser una colección fortuita y fluctuante de individuos, sin un carácter definido y sin un destino compartido (Parekh, 1993, pp. 236-251). La operación teórica clave de esta perspectiva de la sociedad implica una inversión radical de los términos de evaluación de proyectos colectivos. Los objetivos de estos deben ser aquellos que resulten ventajosos para los individuos, y las ventajas que ofrece una sociedad son estrictamente aquellas que los individuos sean capaces de percibir y no aquellas que sean destacadas por historiadores, ideólogos u hombres de Estado. Lo que justifica a una sociedad son las ventajas tangibles y concretas que ofrece a sus miembros aquí y ahora y nada más. Este humano-centrismo liberal es evidente en el atractivo que ahora ejerce el concepto de "soberanía individual" en los círculos de la gobernabilidad internacional. Kofi Annan, Secretario General de la ONU entre 1997-2006 invocó este concepto para cuestionar las flagrantes violaciones que se cometen en nombre de la "soberanía” de algún Estado. Así, un Estado que no puede garantizar la soberanía de los individuos que habitan dentro de sus fronteras es un Estado que no ejerce la única soberanía digna de ese nombre. El todo (soberanía nacional) debe ser equivalente a la suma de sus partes (soberanía individual), es decir, a la suma de "los derechos humanos y libertades fundamentales de todos y cada uno de sus ciudadanos" (Danspeckgruber, 2002, p. 2).

2. De esta forma, se le ha cerrado el paso a las aspiraciones de soberanía que no partan del único objetivo que se considera ahora digno

4 Las ideas y reflexiones vertidas en el apartado teórico son resultado de extensas charlas sobre el tema con David Mena Alemán. 
de su ejercicio: la eficaz protección de los derechos humanos. Así también se ha cerrado el paso a los candidatos al ejercicio de la soberanía, que carezcan de una representación con procesos claramente democráticos. No hay ya sujetos colectivos dignos de ser escuchados en el ámbito internacional que no hablen por un demos efectivamente organizado y representado. La calidad de la voz de aquel que reclama soberanía se discierne en la meticulosidad y corrección de los procedimientos mediante los cuales capta y articula la voz del pueblo, entendido este como una colección de grupos sociales diversos. Cualquiera que reclame soberanía al margen de un soporte procedimental habla como sujeto individual o faccional, a título propio, pero no como sujeto enteramente colectivo. El self del self-government debe ser un self robusto, cabalmente articulador de la voluntad de los individuos que integran la nación para que pueda ser tomado en serio por la comunidad internacional. Lo que importa entonces es cómo se construye la expresión de soberanía y no el contenido de la expresión. En estos términos solo las democracias califican como entidades capaces de proferir expresiones auténticas de soberanía. La implicación básica de este requisito, y sobre el que se abundará más adelante, es que cuando una subcultura o sub-comunidad imaginaria busca romper su condición de subordinación de una entidad nacional y constituirse en nación (autodeterminación externa), las instituciones de gobernabilidad internacional le sugerirán fuertemente que se conforme con la aspiración más modesta de autonomía o federalismo democrático (autodeterminación interna). La democracia tiene ahora mayor valor que la independencia y la consideración fundamental aquí es que la democracia puede hacer más por el bienestar de los individuos que "la pendiente resbalosa hacia la independencia” (Danspeckgruber, 2002, p. 2). Por lo demás, la comunidad internacional no tiene ningún interés en que se amplíe el número de sujetos auto designados como sujetos colectivos propensos a hacer reclamos de soberanía personales o de facciones. Obviamente, desde esta perspectiva teórica liberal, los sujetos que tienen aún menos cabida son aquellos que se encuentran en la búsqueda de la autonomía desde una forma pre-figurativa de construir la política (Brissette, 2016). Al respecto, pueden revisarse los casos de los zapatistas en el sur mexicano y los cosacos en Asia central como ejemplos, no solo de una forma distinta de concebir las relaciones sociales, sino de resistir a los universales creados por la narrativa liberal (Grubačic y O’Hearn, 2016).

3. La preocupación por el binomio derechos humanos y democracia ha infligido otro recorte devastador a los conceptos de soberanía y autodeterminación, dado que dicha preocupación sustrae del ámbito de gobiernos nacionales un gran número de asuntos que se concebían tradicionalmente como internos. Si lo personal es lo político y lo personal concierne a un derecho humano o a una libertad democrática, entonces lo personal es globalmente político. Derechos humanos y democracia se conciben ahora como puntos centrales de una agenda humana común que es objeto de una política cosmopolita y transnacional, llevada a cabo por organizaciones de una sociedad civil global, que intervendrán políticamente en donde estimen que el avance de esa agenda está siendo indebidamente estor- 
bada. Así, pues, los asuntos de derechos humanos y de libertades democráticas en tanto tema de "interés global" dejan de ser potestad exclusiva de las autoridades nacionales. Preocupaciones por el bienestar del género humano prevalecen sobre preocupaciones sobre ámbitos de responsabilidad y de soberanía. Más aún, autoridades nacionales deben rendir cuentas sobre su gestión en esas áreas no solo a sus ciudadanos sino también a la sociedad civil internacional. Pretender hacerlo así es un requisito crucial para que países establecidos sean tratados como participantes respetables en el sistema político internacional. La baja probabilidad de hacerlo así es lo que descartaría a muchos movimientos secesionistas de recibir reconocimiento internacional y, por tanto, de recibir la licencia para operar como nación independiente.

Se percibe, en un primer momento, un declive del nacionalismo cívico y un auge del supranacionalismo instrumental que apela a las nociones más elementales del cosmopolitismo. La idea de pertenecer a una comunidad política relativamente homogénea, integrada por una lengua oficial y sujeta a un marco legal único de aplicación universal e indiscriminada, ha venido perdiendo gradualmente su atractivo, sin dejar de notar que en los últimos años ha existido una especie de redimensionamiento de las posturas más radicales bajo la consigna de un nacionalismo étnico5.
Esto en parte por el "expediente negro" del génesis nacionalista: supresión de idiomas o dialectos secundarios o regionales, para facilitar protagonismo del idioma oficial; marginación de historias o memorias colectivas regionales o locales, para favorecer la asimilación de una macro-historia lineal, sintetizada y fácil de digerir, y desde luego, el ocultamiento de las acciones represivas y la lista de víctimas del Estado en su afán de reforzar la identidad nacional cuando esta no se reconociera de motu proprio; en otras palabras, el desplazamiento de la comunidad concreta, definida como la condena a la socialidad de la que habla Echeverría (1998), por la comunidad imaginada de Benedict Anderson. Esto ocurre en parte por la eficacia con la que el nacionalismo cívico concretó la "condición de igualdad ante la ley". Aquí se argumenta que la igualdad jurídica y política hizo inevitable el reconocimiento de diferencias desde étnicas, religiosas, de género, regional y hasta de preferencia sexual, planteadas por aquellos ciudadanos cuyas características distintivas estaban excluidas de los referentes nacionales. Todo esto, por ejemplo, lleva a satanizar al etno-nacionalismo y a promover nuevas visiones de identidad como el "homonacionalismo" que plantean la necesidad de pensar el nacionalismo también desde la inclusión de la diversidad sexual (Puear, 2013, pp. 336-339).

\footnotetext{
5 Un supuesto inicial para explorar este tema, es que la narrativa del cosmopolitismo genera en su discurso una tensión clara no solamente al desplazar las posturas del nacionalismo cívico, sino también con las del étnico. En el marco de estas tensiones es que se inscribe la crisis más reciente respecto a este tópico, en donde las bases populares han reaccionado enérgicamente a los discursos del aparato político oficial que enarbola un retorno a los valores más conservadores del nacionalismo. En este ámbito es que se explica la emergencia de los grupos ultranacionalistas en los Estados Unidos y su interpelación con la administración de Donald Trump, por ejemplo.
} 
Una vez que se fueron reconociendo las diferencias antes soslayadas, la categoría de nación se volvió demasiado elusiva; se acepta ahora, por ejemplo, que países como Gran Bretaña y España constituyen Estados multinacionales -incluso, se habla de las muchas culturas, identidades $\mathrm{y}$ tradiciones que constituyen y enriquecen a la nación-. Se rechazan también símbolos y referentes de identidad por su conexión a grupos hegemónicos dentro de una nación. En vista de estos procesos se antoja un tanto obsoleto que alguna entidad colectiva pretenda constituirse en una nación independiente como para repetir los vicios y contrasentidos del nacionalismo cívico. Lo que se cuestiona sobre este asunto particular es si se puede sostener, de manera coherente, que una región, quizá Quebec, en realidad tenga una población homogénea, pueda y deba compartir una sola lengua oficial, y que todos sus ciudadanos se sujeten en iguales términos a un solo marco legal. Todo esto, sin reforzar símbolos nacionalistas excluyentes, sin tener que implementar una política educativa que haga obligatorio el uso del idioma oficial $y$, finalmente, sin tener que terminar por hacer ajustes al marco legal para acomodar diferencias que solo se harán patentes hasta el nacimiento de la nueva nación. El problema es que persiste una duda, sólida y documentada, de que pueda surgir una nación que no termine siendo opresiva en algún momento y de alguna forma con respecto a sus propias minorías.

Ahora bien, más allá de la mitología de los nacionalismos está la preocupación, estricta- mente pragmática, de contar con una forma de asociación que garantice seguridad, viabilidad económica y la defensa efectiva de los derechos individuales y civiles. La alternativa del Estado nación soberano, no parece ser una opción con mucho futuro para garantizar particularmente la seguridad y viabilidad económica. El caso de la Unión Europea parece sugerir que estos objetivos pueden alcanzarse en un marco que permita la asociación entre varios Estados.

Todo esto apuntaría a que la alternativa del futuro, desde la práctica hegemónica, no es el nacionalismo sino el supranacionalismo. En este sentido, se sugiere que las ventajas que ofrece una entidad supranacional pueden desincentivar y restar sentido lógico a la secesión, y al énfasis en la autodeterminación por parte de entidades colectivas regionales dentro de alguna de las naciones europeas. Por un lado, es evidente, en términos de seguridad, integración económica y libre tránsito de mano de obra, que cualquiera de las naciones europeas puede lograr más dentro del marco supranacional que por su propia cuenta. Esto debe ser evidente para candidatos potenciales a la secesión como Escocia, Euskadi o Cataluña. Por otro lado, no tendría mucho sentido aspirar a la autodeterminación con respecto a un Estado para, inmediatamente después, aspirar a la integración dentro de una comunidad más amplia y ceder parte de esa soberanía deseada, a una entidad supranacional como sería el caso de la Unión Europea ${ }^{6}$.

Sin embargo, el voto mayoritario de los británicos para salir de la Unión Europea rea-

\footnotetext{
6 Quizás esto pueda ser mejor explicado bajo los principios de la realpolitik. En realidad, las acciones que los Estados ejercen tienen que ver mucho más con la consecución de alguna medida en términos pragmáticos, que con un ordenamiento lógico en cuanto a su congruencia filosófica y política.
} 
bre este debate. Corrobora, en primer lugar, que el sistema internacional no es estático. Demuestra también que una entidad supranacional como la Unión Europea puede sufrir serias fracturas que pongan en tela de juicio su viabilidad. También, abre la puerta, al menos en el caso, para que cualquier reclamo soberanista encuentre eco siempre y cuando se haga por la vía democrática.

\section{NACIONALISMO, COSMOPOLITISMO Y EL DERECHO A LA AUTODETERMINACIÓN DE LOS PUEBLOS EN LA PRÁCTICA}

Los detractores del derecho a la autodeterminación (Spencer y Wollman, 2002; Dittgen, 2003; Dahbour, 2013; Hilpold, 2017) consideran que la lucha por el reconocimiento de los particularismos pone en riesgo cualquier posibilidad de organización, porque nunca terminarían los reclamos soberanistas. Aquí se habla del barril sin fondo de los particularismos. ¿De qué forma lograrían coincidir individuos, grupos y colectividades más o menos amplias, si todos ellos, en algún momento, apelaran al derecho a la autodeterminación y a la soberanía? En otras palabras, existen posibilidades reales de que las aspiraciones por la autodeterminación nunca concluyan, y que un nuevo Estado-nacional contenga o llegue a generar en su interior otras subunidades políticas, culturales y económicas que aspiren, a su vez, a la independencia y a la secesión.

Incluso hay quienes consideran, como Herbert Dittgen (2003, p. 229), que la insistencia violenta por el derecho a la autodeterminación probablemente será la causa de los conflictos en el mundo en los próximos años.
Dittgen sostiene esta idea basándose en la experiencia yugoslava, que dio como resultado nuevas fronteras y fundó nuevas naciones, con el propósito de garantizar a las minorías su derecho a la autodeterminación. Precisamente esta no ha sido una solución satisfactoria al problema, ya que las nuevas fronteras inevitablemente generan otras minorías y, a su vez, nuevos conflictos.

\subsection{Nacionalismo y autodeterminación no cosmopolitas}

Retomando la perspectiva macroscópica de la sociología histórica, el Estado nacional moderno tarde o temprano entra en contradicciones y genera conflictos entre los microacontecimientos, el conjunto, la estructura o el sistema. Esto sucedió en el caso negativo emblemático del nacionalismo y la búsqueda de la autodeterminación de los pueblos ocurrido en Yugoslavia. El país, ficticio como cualquier otro, encontró a principios del siglo xx razón para existir, en un contexto de disolución de los viejos imperios europeos en 1918. Tras la segunda guerra mundial, y en el marco de la guerra fría, logró mantener su integridad, pero las trasformaciones en Europa y el mundo a finales del siglo xx pusieron en tela de juicio su eficacia y legitimidad.

En el caso de Yugoslavia, primero se separaron, sobre la base de una identidad y una historia particular, Eslovenia y Croacia. Posteriormente, se separaría Bosnia-Herzegovina y, por cuestiones étnicas, se propuso en el plan Carrington-Cuterelio (primavera 1992) que se dividiera en tres regiones. Ese plan fracasó como indica Stavenhagen (2000, p. 371), y 
después de la Conferencia de Londres (agosto 1992), se consolidó el plan Vance-Owen que nuevamente dividía a Bosnia-Herzegovina en diez cantones, "nueve de los cuales estaban basados en el dominio de uno u otro de los grupos étnicos" (Kaldor, 2001, pp. 82-83). El conflicto continuó hasta que las presiones estadounidenses lograron un alto al fuego en 1994. El resultado fue el Acuerdo de Washington que, nuevamente, dividía el territorio en cantones más pequeños y dominados por una u otra etnia. Hasta que se firmó el Acuerdo de Dayton en 1994, la violencia y la limpieza étnica (objetivo de la guerra según Mary Kaldor) crecieron en la medida que el territorio se dividía para satisfacer las pretensiones de autodeterminación de los grupos étnicos esparcidos a lo largo y ancho de la geografía balcánica. Ante tal evidencia, Dittgen (2003, p. 229) sugiere que la integración en un Estado-nacional federal, que reconozca su riqueza plural parece ser la mejor solución al problema de las identidades locales y su derecho a la autodeterminación.

Lo que le preocupa a Dittgen y a otros autores es la posibilidad de un serio problema que Spencer y Wollman (2002, p. 143) denominan "regresión infinita". Si el principio de autodeterminación se toma como un derecho absoluto, nos podría conducir prácticamente a un número infinito de reclamos. Por otro lado, el derecho a la autodeterminación, entendido como un derecho fundamental de cualquier Estado-nacional, choca con el mismo principio del Estado-nacional ya formado e instituido, para afrontar y resolver sus propios asuntos. Sobre todo, los relacionados con el principio de soberanía, como también indican Spencer y Wollman (2002, pp. 143-144).

Por lo tanto, la comunidad internacional enfrentaría dos problemas tan graves como difíciles de resolver. Primero, la posibilidad de fragmentar indefinidamente cualquier entidad política que contenga, en su interior, cualquier tipo de reivindicación ya sea étnica, histórica, religiosa o económica. Segundo, si un grupo apela a su derecho a la autodeterminación, enfrentaría a un Estado-nacional consolidado y que lucharía por su unidad, apelando también al mismo derecho. Esto implicaría poner en riesgo la integridad legal que le otorga poder y soberanía a los Estados-nacionales.

De ninguna forma se desprecian aquí las aspiraciones legítimas que pudieran fundamentar los valores y objetivos de los pueblos. Sin embargo, se plantea que la experiencia reciente arroja ejemplos de violencia secesionista (Yugoslavia) que preocupan a la comunidad internacional $y$, al mismo tiempo, nos sugiere un barril sin fondo que debilita la idea misma de Estado-nacional. Para que surja un Estado-nacional nuevo, tendría que dividirse uno ya existente. Por lo tanto, ese nuevo Estado-nacional nacería debilitado, ya que su surgimiento implicaría la destrucción jurídica de conceptos fundamentales como la autodeterminación y la soberanía ${ }^{7}$. El riesgo

\footnotetext{
En definitiva, no realizamos un juicio de valor sobre este proceso al que podríamos denominar de balcanización, por lo que el análisis presente no muestra una postura política. En cualquiera de los casos, esta fragmentación infinita conforma una amenaza para los Estados nacionales como los conocemos, lo que significa al mismo tiempo una amenaza para el orden de dominación actual.
} 
de "separarse" para ser libre e independiente, conlleva la debilidad de esa libertad e independencia que de poco le sirvieron a un Estadonacional ya existente y que sufrió un proceso de secesión. Surge entonces un tercer problema. Ese nuevo Estado-nacional, con la finalidad de fortalecerse jurídicamente y estructurarse de manera homogénea, amedrentaría cualquier tipo de reivindicación de la diferencia y la originalidad. Con el propósito de convertirse en "uno e indivisible", algún grupo, comunidad o pueblo que luche por su autodeterminación señalará y fustigará y pondrá en peligro a todos aquellos que, dentro de sus fronteras, sean percibidos como extraños, ciudadanos de segunda o ajenos al nuevo proyecto soberano.

Por supuesto, no todo proyecto soberanista garantiza la consolidación del ideal humanocéntrico o cosmopolita. A los ejemplos de experiencias recientes poco exitosas, se suman ciertos casos cuya tendencia a la anarquía y la violencia preocupa a la comunidad internacional. Se plantean, por lo tanto, en un ejercicio prospectivo y fundamentado en la historia reciente, cuatro escenarios de desviación en lo que a la lucha por la autodeterminación se refiere.

1. Escenario de secesión con guerra prolongada y violencia terrorista. En este escenario, la guerra prolongada puede ser entre el Estado central y los Estados secesionistas. Un caso relevante es el conflicto étnico entre el Estado central de Sri Lanka y los rebeldes tamiles del sur del país (Ganguly y Taras, 1998, pp. 184-196). Podemos considerar que este conflicto pasó de la estrategia terrorista y de asesinatos selectivos durante los años 70 , hacia una escalada de la violencia desde 1983 con repercusiones internacionales, ya que la India, país vecino de Sri Lanka, tiene cerca de
80 millones de tamiles en la provincia sureña de Tamil Nudu como lo indican Ganguly y Taras (1998, pp. 198-199). Esta dimensión internacional incluye la compra de armamento por parte del gobierno de Sri Lanka con la finalidad de combatir a los tamiles, y amenazaba con desencadenar una guerra de larga duración debido al incremento de las hostilidades.

Las posibilidades de que algunos movimientos secesionistas desemboquen en guerras prolongadas incluyen el caso de Rusia contra Chechenia, contra Georgia, y Osetia, el de Cachemira que involucra a dos Estados con armamento nuclear como India y Pakistán (Allison, 2001, p. 253) y el del Congo (Ganguly y Taras, 1998, p. 227). En este escenario se deben incluir también las posibilidades de que grupos terroristas mantengan acciones violentas contra la metrópolis, como ocurre con el caso del Partido de los Trabajadores de Kurdistán en abierta lucha por la autodeterminación en contra del gobierno turco. Como se verá más adelante, para las reivindicaciones separatistas europeas como la norirlandesa o la vasca, el terrorismo ya no es fuente de legitimidad.

\section{Escenario de secesión con limpieza étni-} ca. La historia reciente cuenta con ejemplos dramáticos y contundentes de la lucha por la autodeterminación y la exacerbación étnica, que revive viejas rencillas culturales y desencadena una serie de odios raciales y religiosos capaces de provocar episodios de genocidio o de limpieza étnica. La limpieza étnica tiene por objeto librar áreas geográficas de etnias no autóctonas. La pertenencia o adscripción geográfica de dichas etnias, es puesta en duda por un discurso nacionalista que reclama un territorio dado como heredad exclusiva de una 
etnia específica. Esta fue la estrategia seguida por la Croacia poscomunista contra bosnios musulmanes en Bosnia-Herzegovina.

El recientemente independizado Estado croata no contaba con una población musulmana considerable dentro de sus límites territoriales que mereciera acciones radicales de limpieza étnica. No obstante, el discurso nacionalista croata auspiciaba acciones extraterritoriales de limpieza étnica en áreas de Bosnia-Herzegovina donde existieran asentamientos de personas de origen croata. La remoción, tanto de personas de origen serbio como bosnio en tales áreas, podía facilitar posteriormente la integración al Estado croata de áreas geográficas limpias. Este objetivo fue frustrado por la comunidad internacional, la cual estableció el protectorado de la Federación Bosnio-Croata de Bosnia-Herzegovina. Como sea, Croacia es un caso ejemplar de un proyecto de secesión alentado por un discurso nacionalista que no estaba confinado a la construcción de un Estado independiente dentro de límites territoriales definidos. El componente étnico de dicho discurso nacionalista no permitía tal confinamiento, en la medida que los miembros de la nación croata estuvieran asentados en áreas fuera de los límites geográficos del nuevo Estado croata. Pero en esta medida también el renacimiento de Croacia como Estado independiente solo podía ser problemático para la comunidad internacional.

Otro ejemplo que puede ofrecerse es el del genocidio en Ruanda por motivos políticos y étnicos en los años noventa entre la élite hutu y los tutsis en el centro oriente de África. Del mismo modo, actualmente el Kurdistán mantiene latente el nivel de conflicto, máxime la crisis en Siria que los ha convertido de nuevo en actores protagónicos de la región. Esto por las rencillas históricas, los potenciales deseos de venganza y asentamientos kurdos dispersos en países vecinos como Irak, Turquía e Irán.

\section{Escenario con inviabilidad económica.} En este sentido hay que referirse a los deseos de autodeterminación de entidades étnicas o culturales que experimentan una profunda dependencia económica con respecto al país del cual se separan, como el caso de las repúblicas caucásicas de la ex Unión Soviética, Timor Oriental e Indonesia o las Islas Åland (Finlandia y sus habitantes suecos en 1920), la Islas Feroe y Groenlandia (respecto a Dinamarca), Madeira y las Azores (respecto a Portugal).

También debe señalarse la carencia grave de capitales locales, las pocas perspectivas de desarrollo económico y, lo más grave, la necesidad de buscar en las ámbitos de la ilegalidad no solo el sustento de la lucha armada, sino el futuro de un país que termine convirtiéndose en un paraíso para el crimen organizado, el tráfico de armas y drogas o cobijo del terrorismo internacional (Afganistán es un ejemplo claro, no de secesión inviable económicamente, sino de la complicidad de un Estado central y las actividades ilegales antes descritas). Esta preocupación ya es central en toda discusión sobre la autodeterminación (Danspeckgruber, 2002, p. 339).

4. Escenario de secesión con riesgos internos potenciales. En este escenario debemos contemplar ciertos casos en donde amplias porciones de la población, se muestren indispuestas a apoyar la independencia o secesión y que podrían convertirse en víctimas, por venganza o segregación, o de un nuevo proyecto nacionalizador. Dos de los más emblemáticos han sido los conflictos en Eritrea y Sudán. Al respecto 
escribe Stavenhagen: "Los regímenes en Addis Abeba y Jartum adoptaron políticas tendientes a terminar con la resistencia e integrar a las regiones en un Estado centralizado y unitario. La violencia era el principal instrumento utilizado en el esfuerzo por someter a los rebeldes" (Stavenhagen, 2000, p. 140). Precisamente porque en un proceso de secesión o de lucha por la autodeterminación, aquellos que desean construir su propio Estado son percibidos como elementos subversivos a los que se debe someter. A su vez, quienes buscan la secesión y la autodeterminación, actúan de la misma forma contra sectores contrarios, ajenos o indiferentes al proyecto secesionista. Así ocurrió, como ya se indicó, en los casos de Sudán y Eritrea (Stavenhagen, 2000, pp. 57-60), en los que el diseño fronterizo ubicó, dentro de un mismo territorio, a poblaciones emparentadas con grupos más allá de los límites nacionales, y que, por razones de vínculos históricos y culturales, se opusieron a la secesión. Un caso contemporáneo es el de los kurdos y las tres distintas facciones que rivalizan por el poder y control del territorio, lo que preocupa no solo a los países vecinos sino a la comunidad internacional por las posibilidades de que un intento secesionista kurdo desemboque en una guerra civil.

\subsection{Nacionalismo y derecho a la autodeterminación cosmopolitas}

Ante la evidencia de que los reclamos nacionalistas y soberanistas no van a cesar ¿¿cuál es la posición de la comunidad internacional? En pocas palabras, intentar preservar la perspectiva humano-céntrica o cosmopolita para legitimar el nacionalismo y el derecho a la autodeterminación. Esto significa defender procesos institucionales, acompañados de la fiscalización de organismos internacionales y legitimados por ejercicios democráticos como consultas ciudadanas y referéndum. Se plantean así tres escenarios que posibilitarían la cristalización de los proyectos soberanistas e independentistas vigentes en el mundo contemporáneo.

1. Escenario de apoyo tácito de la comunidad internacional. En la historia reciente hay dos procesos que claramente lograron su consolidación gracias al apoyo mayoritario de la comunidad internacional: Timor Oriental y Montenegro. Timor Oriental logró su independencia tras un voto abrumador en el referéndum de 1999, siempre con el apoyo de las Naciones Unidas que administró el territorio hasta 2002 cuando se declaró formalmente su independencia. De igual forma, el referéndum de 2006 le otorgó la independencia a Montenegro respecto a Serbia gracias al tácito apoyo de la Unión Europea. Queda claro, en ambos casos, que la comunidad internacional se involucró con la causa secesionista gracias a la legitimidad de consultas democráticas y a las negociaciones de la onu y Australia con Indonesia y a las presiones de la Unión Europea hacia Serbia respecto a Montenegro. Sin embargo, Timor Oriental sigue siendo la nación más pobre del sudeste asiático ${ }^{8}$ y no

8 BBC Mundo. (30/08/2004). Timor Oriental cinco años después. Disponible en: http://news.bbc.co.uk/hi/spanish/international/newsid_3612000/3612362.stm 
es, a todas luces, un ejemplo de viabilidad económica. Caso contrario al de Montenegro que mantiene abiertas las fases de negociación para su ingreso a la Unión Europea (Consejo Europeo, 2015).

Sin embargo, tampoco es una garantía el apoyo de la comunidad internacional y tal es el caso del Sahara Occidental. En un proceso de descolonización iniciado en 1976, y que se tornó violento hasta 1991 con los acuerdos de paz firmados ante la comunidad internacional, la ONU no ha logrado concretar la Resolución 1540 alcanzada durante la Xv Asamblea General del organismo en 1960 para ejercer el derecho a la autodeterminación de los pueblos colonizados en África (Fuente, 2011). En este caso, confiar en los procesos institucionales marcados por los organismos internacionales, según la retórica cosmopolita, no garantiza un resultado favorable para la comunidad subnacional que busca su independencia (Rodríguez, 2017). Lo mismo podría decirse de Palestina, como ejemplo de que el derecho a la autodeterminación de los pueblos bajo la guía cosmopolita de las instituciones internacionales transita con lentitud, siempre que los intereses de algunas potencias se interpongan en su conquista por la independencia. En este sentido, resuena la idea de que el ideal cosmopolita no garantiza el éxito de los reclamos soberanistas.

2) Escenario de procesos de autodeterminación que cancelen tácitamente la lucha armada. La lucha armada por la independencia siempre fue legítima para el colectivo secesionista e ilegítima para la metrópoli perdedora. Sin embargo, todas las naciones contemporáneas consagran su independencia como un logro que necesitó de la violencia y de actos heroicos.
Sin embargo, para la sensibilidad occidental contemporánea y para la comunidad internacional, en la medida en que un proyecto de autodeterminación deponga las armas, será un proyecto viable. Esto se vuelve particularmente obvio después de los atentados del 11 de septiembre de 2001 en Estados Unidos. El terrorismo como arma para la lucha independentista simplemente perdió su legitimidad en Europa. El Ejército Republicano Irlandés anunció el fin de su lucha armada a finales de 2001 precisamente motivados por los resultados de los ataques terroristas del 9-11. Después de diversas negociaciones declaró en julio de 2015 que dejaba la lucha armada. Por su parte, el grupo separatista vasco ETA, anunció en octubre de 2011 el fin definitivo de la violencia terrorista (Aizpeolea, 2011). En ambos casos, el terrorismo dejaría de ser un arma legítima para convertirse en violencia incivilizada que todos los europeos descalifican, particularmente ante el uso de dicha estrategia por el integrismo islámico.

Sobra decir que la eliminación de la violencia como mecanismo para alcanzar la independencia de un reclamo soberanista, se enmarca fácilmente dentro de los parámetros ideológicos del cosmopolitismo liberal. Esto condenaría la lucha armada, por ejemplo, en el caso palestino o del Kurdistán. Pero tampoco resuelve el problema del ideal cosmopolita en el diseño del "nuevo Estado nacional". Es evidente que existen otro tipo de reivindicaciones que van más allá de la configuración Estado-centrista y humano-céntrica que no contemplamos en el grueso del trabajo por sus limitaciones naturales, pero que vale la pena mencionar. Nos referimos a los movimientos 
más críticos contemporáneos que encuentran en estas dos narrativas caras distintas de la misma moneda. Las reacciones frente al antagonismo provocado por el capital han generado posturas que van más allá de la identidad y, por lo tanto, de la reivindicación del Estado nacional. La dinámica de estos movimientos puede ser comprendida como "grietas", utilizando la categoría de Holloway (2010), a los callejones sin salida del debate que hemos ilustrado?.

3. Escenario de procesos de autodeterminación "democráticos". El tercer escenario plantea que la única vía legítima para la autodeterminación de los pueblos es la democrática o la democracia cosmopolita (Baogang, 2003, pp. 204-207). Los proyectos separatistas de Quebec con dos referéndum en 1980 y 1995 (Hanna, 1999; Cameron, 2017), Escocia con el referéndum de 2014 (Casanas, 2014; Sharkey, 2016) y Cataluña (Blanque y Abdelrehim, 2014) con un intento infructuosos de consulta ciudadana convocada para el referéndum del 9 de noviembre de 2014 y en un segundo intento de referéndum en 2017, son ejemplos claros de la retórica nacionalista y separatista de corte cosmopolita y que pone en el centro el ideal humano-céntrico. En todos los casos, los procesos han ido acompañados de acciones políticas encarnadas por partidos y grupos reconocidos por la sociedad. Siempre se apela a un "nuevo estado de cosas" justificándose en los cambios económicos, políticos y sociales.
En los tres casos, los reclamos soberanistas se hacen sobre la base de que la comunidad política mayor, es decir, Canadá, el Reino Unido y España, debe aceptar el ideal humano-céntrico y cosmopolita si este va acompañado de un proceso libre y democrático.

Tras el referéndum de junio de 2016 que apoyó la salida del Reino Unido de la Unión Europea, el espacio para negar otros referéndum, ya sean a escala nacional (Escocia y Cataluña) o a escala supranacional, como proponen los nacionalistas franceses y holandeses para dejar la Unión Europea, el ideal humano-céntrico y cosmopolita se vuelve en contra de los gobiernos liberales y progresistas. Si bien, de alguna forma, garantiza procesos no violentos, deja también sin armas discursivas a los gobiernos centrales de las naciones o de la Unión Europea para impedir consultas ciudadanas democráticas. Sin embargo, esto tampoco garantiza que el diseño del referéndum como instrumento de consulta resulte transparente, incluyente y ajeno a la manipulación de las normas e instituciones democráticas por parte de los actores involucrados. El caso catalán de 2017 está lleno de reclamos por la "ilegalidad de la convocatoria" de parte de los independentistas catalanes, como por las posturas contra el referéndum del gobierno nacional. De igual forma, los discursos antagonistas y descalificadores se intensificaron entre las partes, generando un ambiente de franca confrontación.

9 Quizá la experiencia zapatista sea la que mejor ejemplifique a lo que nos referimos; no obstante, hay otros movimientos que comparten características similares. 


\section{CONCLUSIONES}

En la medida en que el ideal cosmopolita se impone en la comunidad internacional como eje para medir y legitimar las pretensiones soberanistas de los pueblos, también se abre un enorme espacio para que los reclamos soberanistas encuentren cause por la vía democrática. Sin embargo, la retórica cosmopolita no garantiza que la comunidad internacional proteja eficazmente el derecho a la autodeterminación de los pueblos en su andar institucional.

Queda claro que el ideal humano-céntrico o cosmopolita pretende eliminar la violencia y disminuir reclamos soberanistas de corte genocida. Pero esta es una aspiración de las democracias occidentales que no necesariamente comparten otros pueblos que justifican la lucha armada acusando a las metrópolis de usar la violencia en contra de ellos. Sin embargo, si ese ideal se expande con la vehemencia que desearían sus promotores, quedaría poco espacio para oponerse a reivindicaciones nacionalistas que propongan vías democráticas para la autodeterminación.

El siglo XXI seguirá siendo testigo de la reconfiguración del mapa global (Brunn, 2000, pp. 28-29), y no solo por el surgimiento de potenciales nuevas naciones, sino también por el posible desmantelamiento de entidades supranacionales como en el caso de la Unión Europea ante el Brexit. El ideal cosmopolita o humano-céntrico es, finalmente, un arma de doble filo, que ayuda a censurar la búsqueda de la autodeterminación por la vía violenta, pero que no podrá evitar la búsqueda de la autodeterminación por la vía pacífica, institucional y democrática. El debate vigente alcanza para visualizar escenarios probables como los descritos en este artículo, pero no logra eliminar los posibles reclamos soberanistas que se ciernen sobre el sistema internacional y que las vías cosmopolitas quizá ayuden a incrementar y legitimar. Tampoco se garantiza que el ideal cosmopolita sea el factor determinante en la conquista de la soberanía de alguna comunidad subnacional. Se trata de un ideal que pretende consolidarse en el imaginario global del rediseño internacional y que acarrea contradicciones y oposiciones que debilitan su apuesta por la paz.

\section{REFERENCIAS}

Adorno, T. y Horkheimer, M. (1987). Dialéctica del iluminismo. Buenos Aires: Sudamericana.

Aizpeolea, L. (2011). ETA pone fin a 43 años de terror, El Pais, 20 de octubre. Recuperado de http:// politica.elpais.com/politica/2011/10/19/actualidad/1319056094_153776.html

Allison, R. (2001). Central Asian Security and the International Context. En R. Allison y L. Jonson (Ed.). Central Asian Security: The New International Context. Washington: Brookings Institution Press.

Anderson, B. (1991). Comunidades imaginadas. Reflexiones sobre el origen y la difusión del nacionalismo. Ciudad de México: Fondo de Cultura Económica.

Appiah, A. (2007). Cosmopolitanism: Ethics in a World of Strangers. New York-London: W. W. Norton $\&$ Company.

Aron, R. (1996). Peace and War. A theory of International Relations. New York: Dobleday. 
Baogang H. (2003). Cosmopolitan Democracy and the National Boundary Problems. En S. Nagel (Ed.), Policymaking and Democracy. Boston: Lexington Books.

BBC Mundo. (30/08/2004). Timor Oriental cinco años después. Recuperado de http://news.bbc.co.uk/hi/spanish/international/newsid_3612000/3612362.stm

Blanque, H. J. y Abdelrehim, Y. (2014). Catalonia and the Right to Self-Determination from the Perspective of International Law. Max Planck Yearbook of United Nations Law Online, vol. 18, I. 1, pp. 532-562.

Bonnet, A. y Piva, A. (Comp.). (2017). Estado y capital. El debate alemán sobre la derivación del Estado. Buenos Aires: Herramienta.

Brissette, E. (2016). The Prefigurative Is Political: On Politics Beyond 'The State'. En Dinerstein, A. (Ed.), Social Science for an Other Politics: Women Theorising Without Parachutes. New York: Palgrave Macmillan, pp. 109-120.

Brunn, S. D. (2000). The Worldviews of Small States: A Content Analysis of 1995 UN Speeches. En N. Kliot y D. Newman (Ed.), Geopolitics at the End of the Twentieth Century. The Changing World Political Map. London: Frank Cass, pp. 28-29.

Cameron, D. (2017). Self-Determination: Canada and Quebec. Social Science Research Council Working Papers. Recuperado de http://webarchive.ssrc. org/working-papers/CPPF_Models $\% 20$ of $\% 20$ Autonomy_1_Cameron.pdf

Casanas, E. (2014). Self-determination and the Use of Referendums: the Case of Scotland. International Journal of Politics, Culture, and Society. March, vol. 27, Issue 1, pp. 47-66.

Consejo Europeo. (2015). Comunicado de Prensa: "Montenegro y la UE abren dos nuevos capítulos de negociación en el proceso de adhesión”. Recuperado de http://www.consilium.europa.eu/ es/press/press-releases/2015/03/30-montenegroeu-open-more-negotiating-chapters-accessionprocess/

Dahbour, O. (2013). Self-Determination without Nationalism: A Theory of Postnational Sovereignty. Temple: Temple University Press.

Dahl, R. A. (1989). Democracy and its Critics. New Heaven: Yale University Press.

Danspeckgruber, W. (2002). The Self-Determination of Peoples. Community, Nation, and State in an Interdependent World. London: Lynne Rienner Publishers.

Dittgen, H. (2003). World without Borders? Reflections on the Future of the Nation-State. En S. Nagel (Ed.), Policymaking and Democracy. Boston: Lexington Books.

Echeverría, B. (1998). Valor de uso y utopía. Ciudad de México: Siglo XxI.

Elias, N. (1994). Elproceso de civilización. Investigaciones sociogenéticas y psicogenéticas. Ciudad de México: Fondo de Cultura Económica.

Foucault, M. (2009). Vigilar y castigar. Nacimiento de la prisión. Ciudad de México: Siglo XxI.

Fuente, I. (2011). Sahara occidental: origen, evolución y perspectivas de un conflicto sin resolver, Instituto Español de Estudios Estratégicos, Documento Marco 08/2011, 13 de julio del 2011. Recuperado de http://www.ieee.es/Galerias/fichero/ docs_marco/2011/DIEEEM08-2011SaharaOccidental.pdf

Ganguly, R. y Taras, R. (1998). Understanding Ethnic Conflict. The International Dimension. New York: Longman, pp. 184-196.

Gellner, E. (1983). Nations and Nationalism. New York: Cornell University Press.

Giddens, A. (2006). Estados nacionales y violencia. Revista Académica de Relaciones Internacionales, No. 5, p. xxx. 
Grubačic, A. y O'Hearn, D. (2016). Living at the Edges of Capitalism. Oakland: University of California Press.

Hanna, R. (1999). Right to Self-Determination in In Re Secession of Quebec. Maryland Journal of International Law, vol. 23, I. 1, pp. 214-246. Recuperado de http://digitalcommons.law.umaryland.edu/ $\mathrm{mjil} / \mathrm{vol} 23 /$ iss $1 / 9$

Held, D. (2010). Cosmopolitanism: Ideals and Realities. Cambridge: Polity Press.

Hilpold, P. (2017). Self-determination and Autonomy: Between Secession and Internal Self-determination. International Journal on Minority and Group Rights, 24, pp. 302-335.

Hobsbawm, E. (1990). Nations and Nationalism Since 1780. Cambridge: Cambridge University Press.

Holloway, J. (2010). Crack Capitalism. London: Pluto Press.

Kaldor, M. (2001). Las nuevas guerras. Barcelona: Tusquets.

Parekh, B. (1993). A Misconceived Discourse on Political Obligation. Political Studies, No. 41, vol. 2, pp. 236-251.

Puear, J. (2013). Rethinking Homonationalism. International Journal of Middle East Studies, No. 45, pp. 336-339.

Rawls, J. (1993). Political Liberalism. New York: Columbia University Press.
Rodríguez, M. (2017). El derecho a la libre autodeterminación de los pueblos y el caso fallido del Sahara occidental. Los límites del cosmopolitismo y la ecosoberanía como propuesta alternativa. Araucaria. Revista Iberoamericana de Filosofía, Politica y Humanidades, año 19, No. 37, pp. 381-403.

Sharkey, C. (2016). The Struggle for Self-determination in Scotland and Bougainville. Indo-Pacific Strategic Papers. Australian Defense College, pp. 1-26. Recuperado de http://www.defence.gov.au/ADC/ Publications/IndoPac/Sharkey_IPSP.pdf

Smith, A. (1988). Nationalism and Modernism: A Critical Survey of Recent Theories of Nations and Nationalism. London: Routledge.

Smith, A. (2010). Nationalism. London: London School of Economics.

Spencer, P. y Wollman, H. (2002). Nationalism. A Critical Introduction. London: Sage.

Stavenhagen, R. (2002). Conflictos étnicos y Estado nacional. Ciudad de México: Siglo xxI.

Touraine, A. (2000). Critica de la modernidad. Ciudad de México: Fondo de Cultura Económica.

Wallerstein, I. (1999). Elmoderno sistema mundial. Vol. 3. La segunda era de la gran expansión de la economía mundo capitalista, 1730-1850. Madrid: Siglo XXI. 